\title{
Uncovering the Role of Motor Performance and Creative Thinking on Sports Creativity in Primary School-aged Children
}

\section{Sara Santos \& Diogo Monteiro}

To cite this article: Sara Santos \& Diogo Monteiro (2021) Uncovering the Role of Motor Performance and Creative Thinking on Sports Creativity in Primary School-aged Children, Creativity Research Journal, 33:1, 1-15, DOI: 10.1080/10400419.2020.1843125

To link to this article: https://doi.org/10.1080/10400419.2020.1843125

曲 Published online: 15 Nov 2020.

Submit your article to this journal $\widetilde{ }$

III Article views: 168

Q View related articles ¿

View Crossmark data \lceil 


\title{
Uncovering the Role of Motor Performance and Creative Thinking on Sports Creativity in Primary School-aged Children
}

\author{
Sara Santos $\mathbb{1}^{\mathrm{a}}$ and Diogo Monteiro (10) \\ aUniversity Institute of Maia (ISMAI) and University of Trás-os-Montes and Alto Douro (UTAD), Vila Real, Portugal; bESECS, Polytechnique of \\ Leiria, Leiria, Portugal; 'Research Center in Sports Sciences, Health Sciences and Human Development (CIDESD)
}

\begin{abstract}
The demand for creativity in sports has attracted great interest, looking for factors that predict and release children's creative behavior. Our aim was to determine the effects of motor skills and creative thinking on sports creativity, according to gender and age. 198 children (7.71 \pm 1.39 years) were recruited. They completed three motor skills tests, the Torrance Test of Creative Thinking and the Creative Behavior Assessment in Teams Sports. Sprint and change of direction (COD) established to be complementary pairs since predicted all the creative thinking (CT) components. COD emerged as a reliable indicator for attempts and originality in game settings. Abstractness of titles emerged as a key component of CT on sports creativity. According to gender, sprint and COD differently predicted the outcomes; in younger ages both were more effective in predicting $\mathrm{CT}$ components. Our findings support an interplay between motor, thinking, and sports creativity, revealing commonalities in the underlying processes responsible for driving $C T$ and novel behaviors in sport. Training programs enforced in motor performance and CT should be included in primary schools' curricula and in youth sports academies, assisting sports scientists, coaches, and teachers to develop more effective enrichment environments for fostering children's creative behavior and sports creativity.
\end{abstract}

\section{Introduction}

Creativity is a key concept of human innovation and an extremely valued disposition in everyday life (Runco, Millar, Acar, \& Cramond, 2010). A usual way to define creativity is the ability to produce something which is both new/original and task/domain appropriate (Sternberg \& Lubart, 1999). Indeed, the criteria for product novelty and appropriateness have long been seen as the hallmarks of creativity. The concept of creativity has been consistently associated with divergent thinking (Runco \& Acar, 2012). Divergent thinking is considered a process of generating diverse solutions to a particular problem and recent reports confirmed that it is a reliable and valid predictor to gauge creativity (Runco \& Acar, 2012). In turn, convergent thinking consists in generate the most appropriate solution to a given problem and relies on logic, high accuracy, and speed (Cropley, 2006). Nevertheless, it is widely accepted that creative productions tapping into divergent and convergent thinking even though other processes are also likely to contribute (Colzato, Szapora, Pannekoek, \& Hommel, 2013). The methodological diversity across the available studies with regard to the assessment of creativity mainly focused on divergent thinking components is considerably broad (Kaufman, Plucker, \& Baer, 2008). In this vein, the Torrance Test of Creative Thinking (TTCT) is a well-established psychometric test widely used to assess creativity (Kim, 2006). The TTCT third edition encompasses the fluency, elaboration, originality, abstractness of titles (titles) resistance to premature closure (closure) components, and thirteen creative strengths (Kim, 2006, 2011). These components are considered as a comprehensive measure of creative potential (Kim, 2006). TTCT validity was reported in the Cramond, Matthews-Morgan, Bandalos, and Zuo (2005) 40-year follow-up longitudinal study through a structural equation model, updated by Runco et al. (2010) a few years later.

The structure of creativity

The ongoing debate whether creativity is domainspecific or domain-general brings considerable implications for sports field. In other words, this debate is intended to clarify if the individuals can be creative in many domains or who are creative in one specific

CONTACT Sara Santos sarasantos_8@hotmail.com; sdlsantos@ismai.pt Development, CIDESD.

Research Center in Sports Sciences, Health Sciences and Human

(c) 2020 Taylor \& Francis Group, LLC 
domain, such as in sports, are not necessarily innovative in other domains (Kaufman, Glăveanu, \& Baer, 2017). In this vein, Plucker and Beghetto (2004) stated that creativity could be both specific and general and such hybrid model suggests that the level of specificity may change with the social context and with the development through childhood into adulthood that results from an evolving commitment toward the domain of interest. This progression could be explained through the Amusement Park Theory, a hierarchic model, that starts from general requirements and advances to more specific levels (Kaufman \& Baer, 2005). Indeed, some studies identify that this higher-order disposition follows erratic patterns across development since children's creativity began to decline around age 6 and a creative slump occurs in the fourth grade, widely acknowledged as a milestone in the creative progress (Kim, 2011). To prevent this slump recent research has investigated several predictors that may encourage and release children's creativity such as physical fitness and motor skills (Latorre Román, Pinillos, Pantoja Vallejo, \& Berrios Aguayo, 2017; Memmert, 2015).

Physical Fitness and motor skills

In recent years, there has been a growing interest in physical activity due to its positive effects on cognitive processes (Alvarez-Bueno et al., 2017; Hillman, Castelli, \& Buck, 2005), that are central to creativity (Colzato et al., 2013). A few studies have shown that cardiorespiratory fitness and motor skills play an important role in creative thinking development during childhood (Blanchette, Ramocki, O’Del, \& Casey, 2005; Colzato et al., 2013; Latorre Román et al., 2017) but the magnitude of their effect remains unknown. Recently, it has been highlighted a relationship between physical fitness and creative cognitive processes. In this regard, Latorre Román et al. (2017) investigated the outcomes of physical fitness on the general creative thinking in primary school-aged children, reporting a positive association between physical fitness, namely the aerobic capacity and the cognitive creativity level. Indeed, highlyphysically fit children display greater creative thinking than less-physically fit children. Accordingly, children who constantly participated in physical education lessons and make sports have higher creativeness levels (Lupu, 2012; Tekin \& Güllü, 2010). On a more finegrained level, in order to avoid creativity measurement as a whole construct, Colzato et al. (2013) focused on the operation of particular creative thinking processes. Specifically, they investigated the impact of acute physical exercise on convergent and divergent thinking in athletes and non-athletes and findings showed a positive effect in both types of intellect.

\section{Motor creativity}

The primary school-aged children are more likely to express their creativity in action or kinesthetically, thus the movement seems to be the most efficient way to manifest their ideas and thoughts (Bournelli, Makri, \& Mylonas, 2009; Grammatikopoulos, Gregoriadis, \& Evridiki, 2012). Motor creativity is considered as the movement production of a novel motor pattern in order to overcome a predefined problem or a bodily expression of an idea or an emotion (Bournelli et al., 2009). The first studies in the field were carried out in the 1980s by Torrance, using the Thinking Creatively in Action and Movement (TCAM) test across 1806 children aged between 3 and 8 years. The author identified a significant increase in motor creativity, specifically marked in ages 7 and 8 years, largely due to motor fluency and motor originality scores, revealing a gradual improvement with the educational level (Torrance, 1981). Thirty years later, Dominguez, DíazPereira, and Martínez-Vidal research (2015) across the evolution of motor creativity during primary education were aligned with the previous outcomes. It seems that once motor creativity is developed, it was retained for a long period of time (Pagona \& Costas, 2008). Further, in a study exploring the commonalities and differences between creative thinking and motor creativity in primary school-aged children, Scibinetti, Tocci, and Pesce (2011) found a significant association between both. Similar results were identified in Richard Lebeau, Becker, Boiangin, and Tenenbaum study (2018), which explored the effects of a three month creative physical education program in cognitive and motor creativity in fourth-grade children. Results also demonstrated that children allocated to the creative program improve their originality in thinking and enhanced motor fluency and motor flexibility outperforming children in the regular program. Nevertheless, little is known about specific guidelines to provide insight within the proper enrichment environmental conditions that should be created in order to support the development of creative motor actions.

\section{Creativity in team sports}

Furthermore, according to several authors (Campos, 2014; Scibinetti, 2019) sports creativity is higher taskspecific than motor creativity since includes performing particular technical and tactical skills from different sports with decision-making requirements. In spite of their clearly inter-dependency, the ability to produce creative behaviors in fast-changing, complex and unpredictable environments may largely differ from 
more stable and controlled settings (Scibinetti et al., 2011). Thus, throughout the study it was adopted the term sports creativity to differentiate both. Sports creativity is aligned with the vision of children' disposition to move and attune under the guidance of the environment and with the ability to solve a specific game problem in a novel, feasible, unexpected, and original way by starting a single act or flowing in a collective action contributing to team success (Santos, Memmert, Sampaio, \& Leite, 2016). Hence, Campos (2014) describes sports creativity as a mental and physical ability at once which should be seen as the bodymind that moves and thinks in a continuous act'. Team sports, specifically invasion games, offer the possibility to children to capture the environmental relevant information, including the teammates and opponents displacements to pursue and generate novel solutions (Memmert, 2009, 2015). These ecological environments dependent on contextual characteristics are driven by the environment, task, and individual constraints. From this perspective, the generation of creative ideas in sports does not rely exclusively on children imaginative potential and specific movement skills; however, it is underpinned with environmental and task constraints placing boundaries on the solutions available (Hristovski, Davids, Araújo, \& Passos, 2011). The role of constraints may aid children in discovering and exploring new and functional solutions during the game (Hristovski et al., 2011). Indeed, constraints manipulation have been put forth as a central tenet in creativity-related frameworks and practice interventions (Santos, Memmert, \& Sampaio, 2020).

In sports field a few holistic and multidimensional models have emerged, such as the Tactical Creativity Approach (Seven D's) (Memmert, 2015) and the Creativity Developmental Framework (Santos et al., 2016). Both highlighted the role of an early diversification, based on the notion that children "sample" in a variety of movements and sports activities involving higher levels of deliberate play and unstructured activities, as a suitable pathway to unleash creative thinking and behavior. Interestingly, Bowers, Gree, Hemme, and Chalip (2014) found a direct positive relation among time spent in unstructured activities during the early years and adult general creativity thinking, as well as, in fluency, elaboration, flexibility, and originality. Otherwise, the results of Memmert, Baker, and Bertsch (2010) indicated that creative players spent more time in unstructured activities. In fact, being involved in diversified environments and unstructured activities will expose children to a larger variability of practice that may act as an interface between motor and cognitive development (Pesce et al., 2019, 2016). In this regard, few studies highlighted similarities in the process underlying both the generation of creative thoughts and movements (Richard et al., 2018; Santos, Jiménez, Sampaio, \& Leite, 2017; Scibinetti, 2019; Scibinetti et al., 2011). Hence, Santos, Jiménez, Sampaio, and Leite (2017) explored the role of the Skills4Genius, a sports creativity-based program, on creative thinking and sports creativity in children, ranging in age from 6 to 10 years. This five-month program demonstrated an increase in specific cognitive creative components such as, elaboration, originality, titles, closure and consequently, in the general creative thinking score. Besides, improved sports creativity such as fluency, attempts, and versatility of several skills performed during small-sided games situations. This study also revealed a relationship between the creative cognitive processes and sports creativity (Santos et al., 2017).

Nevertheless, to our knowledge, no research has addressed the extent to which motor performance and creative thinking contribute to release sports creativity in children. Thus, their role in the underlying processes related to sports creativity still remain unclear. Accordingly, this study aimed to explore the path analysis effects of motor performance and psychometric indicators of creative thinking on sports creativity outcomes. Specifically, was tested the association of COD, sprint, and vertical jump in thinking fluency, elaboration, originality, closure, and titles, in turn, we explored whether previous components were predictors of the in-game attempts, fluency, versatility, and originality by means of structural equation modeling. In addition, we analyzed the direct and indirect effects of each variable between males and females and younger (6 to 8 years) and older ( 9 to 10 years) children. This study supports the view of creativity as a multifaceted construct and it is intended to provide further evidence in a potential interplay across motor, cognitive, and movement features. Therefore, it may be expected some commonalities between specific components of creative thinking and sports creativity with no gender differences. In turn, possibly achieving adequate motor skills during the early ages will substantially impact the thinking and sports creativity.

\section{Material and methods}

\section{Participants}

The participants were 198 children from several primary schools in northern Portugal range from 6 to 10 years old - mean age: $7.71 \pm 1.39$ years; height: $130 \pm 8.39 \mathrm{~cm}$ : weight: $28.6 \pm 6.65 \mathrm{~kg}$; body mass 
index (BMI): $17.1 \pm 2.76 \mathrm{~kg} / \mathrm{m}^{2}$; sport starting age: $5.4 \pm 1.7$ years; number of sports practiced: $1.4 \pm 0.6$; accumulated months (structured): $34.7 \pm 20.6$; accumulated hours (structured): $311.2 \pm 336.1$; accumulated hours (unstructured): $472.2 \pm 535.7$ - in which 96 were girls and 102 boys. The starting point of the previous accumulated values is age 2 and it was considered a year-by-year description. Previous experiences in sports and screen time information are outlined in Table 1, while detailed parents' characteristics are listed in Table 2. A verbal description of the nature and purpose of the study was given to the children's parents and school supervisors. Parental consent was obtained for the participants. Initially, 300 participants were recruited; 102 were excluded due to the following reasons: (i) consent form not returned,

Table 1. Participants previous experiences in sports and screen time.

\begin{tabular}{lc}
\hline & $(\mathrm{M} \pm \mathrm{SD})$ \\
Previous experiences in Sports & $\mathrm{n}=198$ \\
\hline Sport Starting Age (total) & $5.4 \pm 1.7$ \\
Male & {$[2-10]$} \\
Female & $5.0 \pm 1.3$ \\
Accumulated Months (structured) & $5.8 \pm 2.1$ \\
& $34.7 \pm 20.6$ \\
Male & {$[4-84]$} \\
Female & $39.3 \pm 24.1$ \\
Accumulated Hours (structured) & $31.1 \pm 18.7$ \\
& $311,2 \pm 336,1$ \\
Male & {$[30-1550]$} \\
Female & $410 \pm 420$ \\
Number of Sports Practiced & $213 \pm 250$ \\
& $1.4 \pm 0.6$ \\
Male & {$[1-3]$} \\
Female & $1.6 \pm 0.8$ \\
Type of Sports Practiced & $1.3 \pm 0.5$ \\
Individual & \\
Collective & $55 \%$ \\
Combat & $29 \%$ \\
Accumulated Hours (unstructured) & $16 \%$ \\
& $472,2 \pm 535,7$ \\
Male & {$[15-3240]$} \\
Female & $590,8 \pm 615,6$ \\
Screen Time & $473,5 \pm 520,2$ \\
Screen Time School Day (min) & \\
Screen Time - Weekend (min) & $98.1 \pm 77.8$ \\
& {$[0-360]$} \\
\hline
\end{tabular}

Table 2. Parents sociodemographic characteristics.

\begin{tabular}{lc}
\hline Factors & $\%$ \\
\hline Education status & \\
Elementary school & $1 \%$ \\
Middle school & $23 \%$ \\
High school & $36 \%$ \\
University & $40 \%$ \\
Marital Status & \\
Married & $87.4 \%$ \\
Single & $5 \%$ \\
Separated/Divorced & $7.3 \%$ \\
Widow & $0.3 \%$ \\
Professional Status & \\
Employee & $92 \%$ \\
Unemployed & $8 \%$ \\
\hline
\end{tabular}

(ii) absence on the days of data collection, and (iii) one of the data collection was missing. Participants with intellectual or physical disabilities were not selected. All participants were notified that they could withdraw from the study at any time. The study protocol was approved by and followed the guidelines stated by the local Institutional Research Ethics Committee and conformed to the recommendations of the Declaration of Helsinki.

\section{Instruments}

\section{Anthropometric measures}

Weight $(\mathrm{kg})$ was measured with a weighing scale (Tanita MC 180) in which participants wearing light clothes and were barefoot. Height $(\mathrm{cm})$ was measured using a wall stadiometer (Seca 220 ${ }^{\circledR}$; Hamburg, Germany) with the child upright considering the sagittal midline touching the back board and will be recorded in centimeters to the nearest millimeter. BMI was calculated by the ratio between weight and squared height $(\mathrm{kg} / \mathrm{m} 2)$.

\section{Previous experiences in sports and screen time}

In order to examine the previous experiences in sports of participants, it was applied on adapted questionnaire validated by Leite, Baker, and Sampaio (2009). Each participant completed the questionnaire designed to gather structured and unstructured experiences. The researchers provided a brief explanation of the questionnaire and remained in the room in order to answer questions. Its completion was designed to take around 15 minutes. To reduce the retrospective bias and to cross-validate the data provided by children, parents were asked to confirm the information. The questionnaire was intended to obtain detailed information regarding: i) main sport starting age: age at child starting his/her practice; ii) number and amount of time spent in structured activities or other sports (formal adult-led sports activities that include all kinds of organized training); iii) number and amount of time spent in unstructured activities such as playing street football or spontaneous practice; and iv) type of structured activities taking into consideration individual, collective, and combined sports in a year-by-year description. Following this procedure, a detailed examination of the participants' school day and weekend screen time was obtained.

\section{Motor skills}

All selected tests are focused on testing basic components of physical fitness and motor development such as change of direction, strength, and running. The 
vertical jump ability was assessed through a free arms countermovement jump using the Optojump System (Microgate $S A R L$, Italy) in order to determine the explosive lower body strength. This test involved the participants lowering themselves from an upright standing position until approximating a knee angle of 90 degrees, followed immediately by a vertical jump as high as possible. They were allowed to swing their arms freely. The test was performed twice and the best score was recorded in centimeters. Lower jumping height indicates poor performance. Instead, the anaerobic performance was evaluated using a straight sprint test. Participants were instructed to run as fast as possible over $15 \mathrm{~m}$ distance with photocell gates places $0.4 \mathrm{~m}$ above the ground. A standing-start position, on a flat, hard, and non-slip surface with the children preferred foot forward and placed exactly $3 \mathrm{~m}$ behind the first timing gate. The $15 \mathrm{~m}$ straight sprint was performed according to Mujika, Santisteban, Impellizzeri, and Castagna (2009) protocol. Two attempts were made for the test and the best time was recorded in seconds. The test score was the running time, with long times indicating poor performance. The change of direction (COD) assessment was evaluated through a modified T-test protocol for young children and its reliability was outlined by Sassi et al. (2009). The modified T-test preserved the same nature of displacement, except for the measures of intercone distance that was reduced to be more representative of team sports requirements. The participants started each trail from a standing position $0.5 \mathrm{~m}$ with both of their feet behind the first timing gate. On command, the participants: 1) sprinted $5 \mathrm{~m}$ forward to the center cone and touched the top of it with their right hand; 2) sidestepped $2.5 \mathrm{~m}$ to the left cone and touched its top with the left hand; 3) sidestepped $5 \mathrm{~m}$ to the far right cone; 4) sidestepped back to the left to the center cone and then 5) ran $5 \mathrm{~m}$ backward to the finish line. The T-test involves speed with four directional changes and it is moderately correlated with sprint and vertical jump (Sassi et al., 2009). Two attempts were made for the test and the best time was recorded in seconds with long times indicating poor performance. The participants repeated the test if they failed to run the course as instructed. The modified T-test and $15 \mathrm{~m}$ straight sprint performance were measured using a witty photocell system (Microgate, Bolzano, Italy).

\section{Creative thinking}

The participants' creative thinking was measured through the Portuguese version of the Torrance Test of Creative Thinking (TTCT), Figural Form A. The TTCT Figural Form A has been translated into over
35 languages and is widely recognized and referenced as a valid and reliable instrument of creative thinking assessment (Runco et al., 2010). It is designed for ages 5 to beyond. The TTCT Figural Form A consists of three timed pencil and paper pictures construction and completion activities, lasting ten minutes each with one minute break between tasks. All of the tasks required unusual drawings that have standard shapes as parts: i) draw a picture, using pear or jelly bean shape provided on the page as a stimulus; ii) finish a drawing, using ten incomplete figures to make a completed object or picture; and iii) compose a different drawing using parallel lines, where children used three pages of lines to create pictures. Moreover, each drawing was scored using five subscales of normreferenced measures presented in the third edition of the TTCT: fluency, elaboration, originality, resistance to premature closure (closure), abstractness of titles (titles), and also 13 creative personality traits that comprise the children's creative strengths. Fluency is the ability to produce a large number of figural images. Elaboration reflects the participant's ability to apply details in order to extend an idea. Originality represents the ability to produce unusual, unexpected, yet relevant ideas as determined by statistical infrequency. The closure is based on the conclusion that creative behavior requires a person to keep an open mind while processing information. Titles are based on the idea that creativity requires an abstraction of thought and measures the degree to which a title moves beyond concrete labeling of the pictures drawn. The creative strengths were not considered in the analysis process, however, they can be described as emotional expressiveness, storytelling articulateness, movement or action, expressiveness of titles, synthesis of incomplete figures, synthesis of lines or circles, unusual visualization, internal visualization, extending or breaking boundaries, humor, richness of imagery, colorfulness of imagery, and fantasy (Kim, 2006, 2011).

\section{Sport-specific creativity}

The participants were divided into two balanced teams of four without a goalkeeper, taking into consideration the physical education teacher subjective evaluation of the children's physical, technical, and tactical skills. The small-sided games (SSG) format was played during four bouts where in the one and three bouts participants played with foot and in the two and four bouts played with hand in a field with four targets. Each bout has a duration of 5-min, interspersed by a 3-min of passive rest between the conditions, accounting a total time of $29 \mathrm{~min}$. The SSG was recorded using two digital cameras, both Sony NV-GS230 from a fixed position 
(frequency was $15 \mathrm{~Hz}$ and the resolution was $1280 \times 720$ pixels).

In-game creative behavior was assessed through a computerized notational analysis using LongoMatch software (Version 1.3.2, Fluendo, Barcelona, Spain). Afterward, the data were organized in a pre-prepared spreadsheet (Excel for Windows ${ }^{\circledR}$ ) entitled Creative Behavior Assessment in Team Sports (CBATS). The CBATS was developed to measure creativity in ball possession during the game performance (Coutinho et al., 2018; Santos et al., 2018, 2017). Measuring creativity in team sports is challenging and commonly, following behaviors are placed in evidence to assess creative behavior in team sports namely pass, dribble, and shot skills which were divided into successful and unsuccessful actions. Previous variables were classified considering the creativity components (Table 3) such as attempts, fluency, versatility, and originality which have been used to describe creative behavior in team sports (Coutinho et al., 2018; Santos et al., 2016). Fluency, versatility, and originality were considered successful actions, while fails and attempts comprised the unsuccessful actions. In this study, originality took into account the criteria related to the rareness of the versatile actions.

Analysis of the previous five components during SSG formats allows capturing the qualitative changes of retained movements' performance embedded in a specific context which is not possible when movement is observed as a single technique in isolation. An experienced sport performance analyst gathered the data and reliability was inspected by retesting $19 \%$ of the sample 2 weeks later. The obtained intra-rater reliability coefficient was high and considered consistent (intra-class correlation >.82) (O’Donoghue, 2010).

\section{Procedure}

After obtaining the appropriate permits from the schools and informed consent from parents the tests were carried out. Anthropometric measurements such as height, weight, and BMI percentage; previous experiences in sports; and screen time were gathered one week before the data collection. The evaluations were carried out over five separate sessions by a team of trained researchers and took place during the physical education classes. The TTCT Figural Form A was administered during the first testing session and answers were scored individually. As recommended in testing guidelines before the administration of the TTCT the participants performed a warm-up activity based on brainstorming to arouse their creative incubation. Still, the researcher invited the participants to enjoy and view the activities as a series of pleasurable challenges in order to minimize intimidating feelings related to a performance-oriented climate. The researcher provided a brief explanation of the TTCT and its completion was conducted in a quiet classroom lasting for 40 minutes (Kim, 2006). Children were presented with the paper and pencil cognitive creativity tasks as a game and were not aware that a 10 minutes timeframe was given for each activity. The researcher remained in the classroom while children were completing the test and were available to answer questions. Aspects of physical fitness were assessed in the second session: vertical jump, COD, and $15 \mathrm{~m}$ straight sprint (two trials, with the best trial registered). Children also completed two familiarization trials before the tests and were assessed individually. The research team demonstrated all the tests beforehand and the children were encouraged to perform as well as possible in every test. Finally, one week later, in the remaining sessions, children performed the SSG intended to assess the sports creativity. Before the assessment, the participants completed a 10-minute standardized warm-up based on ball possession games without goals and recreational games. The game behavior was assessed during a $4 \mathrm{v} 4$ game played on $18 \times 12 \mathrm{~m}$ (length $\mathrm{x}$ width) indoor pitch using pop-up goals. This SSG format was chosen since it favors the emergence of technical actions while promoting team-related and self-organized behaviors through better coupling the players' actions to environmental information (Aguiar, Goncalves, Botelho, Lemmink, \& Sampaio, 2015; Coutinho et al., 2018). Indeed, according to the above-mentioned references, the $4 \mathrm{v} 4$ is the minimal format where all offensive and defensive fundamental principles of the game are considered. Several balls were placed around the field to ensure the replacement as fast as possible. No feedback or encouragement was allowed during the game conditions. The children were stimulated to hydrate with water before the SSG and also in-between the bouts. All the SSGs were performed at the same hour of the day.

\section{Plan of analysis}

Descriptive statistics, including means and standard deviations as well as bivariate correlations were calculated for the variables under analysis. The required sample size was determined through $G^{*}$ Power 3.1 (Faul, Erdfelder, Buchner, \& Lang, 2009), considering the following parameters: effect size $\mathrm{f}^{2}=.10 ; \alpha=.05$; statistical power $=.95$; number of tested predictors 4 and total number of predictors 8 , as suggested by Dennis (2019). The minimum sample size required 
Table 3. Description of the creative components measured through the creative behavior assessment in team sports.

\begin{tabular}{|c|c|c|c|}
\hline \multicolumn{3}{|c|}{ Creative Components } & \multirow{2}{*}{$\begin{array}{l}\text { Behavioral Descriptions } \\
\text { A standardized pass does not } \\
\text { reach the intended teammate }\end{array}$} \\
\hline Pass & Unsuccessful & Fail & \\
\hline & & Attempt & $\begin{array}{l}\text { The pass does not reach the } \\
\text { receiver, but the player tries to } \\
\text { explore a nonstandardized } \\
\text { action (non-effective) }\end{array}$ \\
\hline & Successful & Fluency & $\begin{array}{l}\text { The participant intentionally } \\
\text { plays the ball from one } \\
\text { participant to a teammate but } \\
\text { in a standardized way (effective) }\end{array}$ \\
\hline & & Versatility & $\begin{array}{l}\text { The pass reaches the receiver } \\
\text { but in a nonstandardized way } \\
\text { (effective and different) }\end{array}$ \\
\hline & & Originality & $\begin{array}{l}\text { The participant considers the } \\
\text { rarity of overall versatile passes } \\
\text { performed during the game }\end{array}$ \\
\hline & $\begin{array}{l}\text { Standardized } \\
\text { behavior }\end{array}$ & & $\begin{array}{l}\text { The participant performs a pass } \\
\text { with the dominant limb and } \\
\text { uses the inside part of the foot }\end{array}$ \\
\hline & $\begin{array}{l}\text { Nonstandardized } \\
\text { behavior }\end{array}$ & & $\begin{array}{l}\text { The participant considers all } \\
\text { executions that are different } \\
\text { from the standardized pass (i.e., } \\
\text { pass with head) }\end{array}$ \\
\hline \multirow[t]{7}{*}{ Dribble } & Unsuccessful & Fail & $\begin{array}{l}\text { Participant in possession of the } \\
\text { ball fails to overcome the } \\
\text { defender when realizing } \\
\text { a standardized dribble }\end{array}$ \\
\hline & & Attempt & $\begin{array}{l}\text { Participant fails to progress in } \\
\text { the pitch or gain a favorable } \\
\text { position when realizing } \\
\text { a nonstandardized dribble }\end{array}$ \\
\hline & Successful & Fluency & $\begin{array}{l}\text { Participant dribbles the } \\
\text { opponent toward progress in } \\
\text { the pitch or moves toward } \\
\text { a more favorable position using } \\
\text { a standardized dribble }\end{array}$ \\
\hline & & Versatility & $\begin{array}{l}\text { Participant dribbles the } \\
\text { opponent toward progress in } \\
\text { the pitch or moves toward } \\
\text { a more favorable position in } \\
\text { a nonstandardized dribble }\end{array}$ \\
\hline & & Originality & $\begin{array}{l}\text { Participant considers the } \\
\text { unusualness of versatile } \\
\text { dribbles performed during the } \\
\text { game }\end{array}$ \\
\hline & $\begin{array}{l}\text { Standardized } \\
\text { behavior }\end{array}$ & & $\begin{array}{l}\text { Participant dribbles around the } \\
\text { opponent using a simple side } \\
\text { touch with the dominant limb }\end{array}$ \\
\hline & $\begin{array}{l}\text { Nonstandardized } \\
\text { behavior }\end{array}$ & & $\begin{array}{l}\text { Participant considers all } \\
\text { executions that are different } \\
\text { from the standardized dribble } \\
\text { (i.e., roulette) }\end{array}$ \\
\hline \multirow[t]{6}{*}{ Shot } & Unsuccessful & $\begin{array}{l}\text { Fail } \\
\text { Attempt }\end{array}$ & $\begin{array}{l}\text { A standardized off-target shot } \\
\text { A nonstandardized off-target } \\
\text { shot }\end{array}$ \\
\hline & Successful & Fluency & $\begin{array}{l}\text { Standardized on-target shot } \\
\text { (the finalization is effective) }\end{array}$ \\
\hline & & Versatility & $\begin{array}{l}\text { Nonstandardized on-target shot } \\
\text { (the finalization is effective and } \\
\text { different) }\end{array}$ \\
\hline & & Originality & $\begin{array}{l}\text { Participant considers the rarity } \\
\text { of versatile shots performed } \\
\text { during the game }\end{array}$ \\
\hline & $\begin{array}{l}\text { Standardized } \\
\text { behavior }\end{array}$ & & $\begin{array}{l}\text { Off-target and on-target shot } \\
\text { with dominant limb, in which } \\
\text { the participant hatted the ball } \\
\text { with the instep, top or inside of } \\
\text { the foot. }\end{array}$ \\
\hline & $\begin{array}{l}\text { Nonstandardized } \\
\text { behavior }\end{array}$ & & $\begin{array}{l}\text { Participant considers all } \\
\text { executions or variations that } \\
\text { were different from the } \\
\text { standardized shot }\end{array}$ \\
\hline
\end{tabular}

was 129 , which was respected in the present study for all samples.

A multiple path regression linear analysis, via Maximum Likelihood (ML) in AMOS 23.0 was performed (Kline, 2016). The standardized direct and indirect effects on the outcomes variables were analyzed in order to test the effects across variables under analysis. Bootstrap resampling (1000 samples), via bias corrected $95 \%$ confidence intervals (CI) was used to assess the significance of the direct and indirect effects. An effect is considered significant ( $\leq .05)$ if its $95 \%$ CI does not include zero (Hayes, 2018; Williams \& Mackinnon, 2008). Effect sizes were evaluated as trivial (0-0.19), small (0.20-0.49), medium (0.50-0.79) and large ( 0.80 and greater), as suggested by Cohen (2013).

\section{Results}

A preliminary analysis revealed that missing values are less than $0.3 \%$, and consequently the Full Information Maximum Likelihood estimation (FIML) were considered for analysis (Cham, Reshetnyak, Rosenfeld, \& Breitbart, 2017). Additionally, no outliers (univariate and multivariate) were founded. Descriptive statistics indicated no deviations from univariate normality (skewness ranged from -1.98 to +1.98 ; kurtosis ranged from -7 to +7 ). However, Mardia's coefficient for multivariate kurtosis exceeded expected values $(>5)$. Therefore, a BollenStine (B-S) of 2000 samples for the subsequent analysis was imputed following Nevitt and Hancock (2001) recommendations.

The variance inflation factor (VIF) and tolerance test were performed to test the collinearity diagnosis (Dennis, 2019; Hair, Black, Babin, \& Anderson, 2019). Results revealed that no collinearity problems were found since all values were less than 10 or greater than .10 in terms of VIF and tolerance tests, respectively. Therefore, the conditions for conducting a regression analysis were met (Hair, Babin, Anderson, \& Black, 2019).

Table 4 shows descriptive statistics' and bivariate correlations among studied variables. In general results revealed that COD and sprint are negatively associated with creative thinking and sports creativity, while vertical jump-free arms are positively associated with both. In addition, variables from creative thinking are positively associated between them as well as the variables from sports creativity. However, only fluency, titles, and closure from creative thinking variables demonstrated an association with sports creativity variables namely with game originality, game fluency, and game attempts. The correlation pattern across above variables varied between weak (e.g., VJFA - GA-SC [.17]) to 
Table 4. Descriptive statistics and bivariate correlations across variables under analysis.

\begin{tabular}{|c|c|c|c|c|c|c|c|c|c|c|c|c|c|c|c|}
\hline Variables & M & SD & Range & 1 & 2 & 3 & 4 & 5 & 6 & 7 & 8 & 9 & 10 & 11 & 12 \\
\hline 1.COD & 9.84 & 1.70 & $5.83-15.12$ & 1 & - & - & - & - & - & - & - & - & - & - & - \\
\hline 2.Sprint & 3.32 & 0.36 & $2.27-4.59$ & $.69^{* *}$ & 1 & - & - & - & - & - & - & - & - & - & - \\
\hline 3.VJFA & 20.08 & 4.75 & $9.90-35.90$ & $-.66^{* *}$ & $-.69 * *$ & 1 & - & - & - & - & - & - & - & - & - \\
\hline 4.Fluency - CT & 23.40 & 8.14 & $1-40$ & $-.19^{* *}$ & $-.31^{* *}$ & $.15^{*}$ & 1 & - & - & - & - & - & - & - & - \\
\hline 5.Elaboration - CT & 6.09 & 2.49 & $3-15$ & $-.34^{* *}$ & $-.25^{* *}$ & $.29^{* *}$ & $.31^{* *}$ & 1 & - & - & - & - & - & - & - \\
\hline 6.Originality - CT & 11.43 & 5.67 & $0-29$ & $-.30^{* *}$ & $-.33^{* *}$ & $.21^{* *}$ & $.76^{* *}$ & $.45^{* *}$ & 1 & - & - & - & - & - & - \\
\hline 7.Titles - CT & 4.87 & 4.86 & $0-20$ & $-.41^{* *}$ & $-.29^{* *}$ & $.34^{* *}$ & $.18^{*}$ & $.57^{* *}$ & $.23^{* *}$ & 1 & - & - & - & - & - \\
\hline 8.Closure - CT & 13.58 & 4.44 & $0-24$ & $-.17^{*}$ & $-.31^{* *}$ & $.25^{* *}$ & $.56^{* *}$ & $.33^{* *}$ & $.43^{* *}$ & $.28^{* *}$ & 1 & - & - & - & - \\
\hline 9.GO - SC & 0.27 & 0.81 & $0-6$ & $-.32^{* *}$ & $-.20^{* *}$ & $.26^{* *}$ & .02 & .06 & .07 & $.16^{*}$ & -.04 & 1 & - & - & - \\
\hline 10.GA - SC & 0.63 & 1.38 & $0-9$ & $-.26^{* *}$ & $-.24^{* *}$ & $.17^{*}$ & .02 & .10 & .03 & $.21^{* *}$ & -.02 & $.48^{* *}$ & 1 & - & - \\
\hline 11.GF - SC & 9.75 & 7.04 & $0-37$ & $-.32^{* *}$ & $-.24^{* *}$ & $.25^{* *}$ & $.17^{*}$ & .12 & .12 & .10 & $.14^{*}$ & $.29 * *$ & $.20^{* *}$ & 1 & - \\
\hline 12.GV - SC & 0.79 & 1.81 & $0-11$ & $-.32^{* *}$ & $-.21^{* *}$ & $.28^{* *}$ & .03 & .01 & .06 & .11 & -.04 & $.73^{* *}$ & $.48^{* *}$ & $.34^{* *}$ & 1 \\
\hline
\end{tabular}

Note. $\mathrm{COD}=$ change of direction; VJFA = vertical jump free arms; $\mathrm{CT}=$ variables from creativity thinking; $\mathrm{SC}=$ variables from sports creativity; $\mathrm{GO}=\mathrm{game}$ originality; $\mathrm{GA}=$ game attempts; $\mathrm{GF}=$ game fluency; $\mathrm{GV}=$ game versatility; $\mathrm{M}=$ mean; $\mathrm{SD}=$ standard deviation; ${ }^{* *}=p<.01 ;{ }^{*}=p<.05$.

strong (Fluency - CT - Originality-CT [.76]), as recommended by Akoglu (2018). The remaining variables do not present a significant association $(p>.05)$.

Table 5, showed the direct and indirect effects across all variables under analysis in a total sample. Results evidence that motor performance, especially COD and sprint negatively predicted some variables of creative thinking namely: elaboration and titles (COD); fluency, originality, and closure (sprint). In its turn, variables from creative thinking particularly titles, positively predicted game originality, game attempts, and game versatility of the sports creativity. The standardized indirect effects indicated that just COD via variables from creative thinking negatively predicted game originality and game attempts. The effects varied from small to trivial. In total the model explains $6 \%$ of game originality, $7 \%$ game attempts, $3 \%$ of game fluency, and $6 \%$ of game versatility.

Tables 6 and 7 demonstrate the direct and indirect effects of studied variables in both male and female children. Results from the male sample, revealed that just COD negatively predicted thinking creativity, specifically titles, and originality. In addition, the variables from thinking do not present any effect with sports creativity variables, except the titles variable, which presented a positive effect with game originality. In terms of indirect effects just COD revealed a significant effect with game originality through creative thinking. The effects fluctuate from small to medium. In total, the model explains $9 \%, 14 \%, 8 \%$, and $6 \%$ of game originality, game attempts, games fluency, and game versatility, respectively. Regarding the results from the female sample some differences were verified compared to the male sample. Specifically variables from motor performance COD and sprint negatively predicted elaboration and originality, respectively, whereas VJFA positively predicted titles. In terms of creative thinking variables, two significant effects between elaboration and game attempts as well as closure and game fluency were founded. The standardized indirect effects revealed that sprint negatively predicted game fluency, whereas vertical jump positively predicted game fluency. The effects varied from trivial to medium. The model explains, $6 \%$ of game originality, $8 \%$ of game attempts, $21 \%$ of game fluency, and $7 \%$ of game versatility.

Tables 8 and 9 show the direct and indirect effects across variables under analysis in both younger (6 to 8 years old) and older (9 to 10 years old) children. Concerning the results from younger, motor performance variables especially COD negatively predicts titles whereas sprint predicts fluency, originality, and closure. In turn, elaboration and titles, both creative thinking variables, negatively and positively predicted game versatility. No standardized indirect effects between motor performance and game creativity were founded. The effects ranged from small to trivial. Results also revealed that the model explains $9 \%$ of game originality, $8 \%$ of game attempts, $6 \%$ of game fluency, and $11 \%$ of game versatility. In relation to the results of older children, just two significant effects between COD and closure and closure and game fluency were established and therefore, some differences with younger children emerged. The effects varied from small to trivial. In total model explains $7 \%, 13 \%, 9 \%$, and $8 \%$ of game originality, game attempts, game fluency, and game versatility, respectively.

\section{Discussion}

Creativity has been a vast construct of questioning to scholars, psychologist, and more lately, physical education teachers and coaches. Accordingly, the aim of this study was to determine the direct and indirect effects of motor skills and psychometric indicators of creative thinking on sports creativity outcomes between males 
Table 5. Direct and indirect effects of regression analysis among all variables regression analysis in all samples.

\begin{tabular}{|c|c|c|c|c|}
\hline Predictors & Path & $\beta$ & $\mathrm{Cl}-95 \%$ & $p$ \\
\hline \multicolumn{5}{|l|}{ Direct effects } \\
\hline \multirow[t]{15}{*}{ Motor Performance } & COD $\rightarrow$ Fluency & .01 & {$[-.226, .221]$} & .932 \\
\hline & COD $\rightarrow$ Elaboration & -.29 & {$[-.466,-.095]$} & .001 \\
\hline & $C O D \rightarrow$ Originality & -.16 & {$[-.370,-.052]$} & .136 \\
\hline & COD $\rightarrow$ Titles & -.36 & {$[-.523,-.167]$} & .002 \\
\hline & COD $\rightarrow$ Closure & .13 & {$[-.047, .306]$} & .157 \\
\hline & Sprint $\rightarrow$ Fluency & -.38 & {$[-.549,-.145]$} & .004 \\
\hline & Sprint $\rightarrow$ Elaboration & .04 & {$[-.143, .236]$} & .645 \\
\hline & Sprint $\rightarrow$ Originality & -.29 & {$[-.476,-.085]$} & .003 \\
\hline & Sprint $\rightarrow$ Titles & .06 & {$[-.129, .220]$} & .526 \\
\hline & Sprint $\rightarrow$ Closure & -.33 & {$[-.526,-.055]$} & .013 \\
\hline & VJFA $\rightarrow$ Fluency & -.11 & {$[-.300, .084]$} & .306 \\
\hline & VJFA $\rightarrow$ Elaboration & .13 & {$[-.085,349]$} & .229 \\
\hline & VJFA $\rightarrow$ Originality & -.09 & {$[-.278, .107]$} & .385 \\
\hline & VJFA $\rightarrow$ Titles & .15 & {$[-.032, .337]$} & .095 \\
\hline & VJFA $\rightarrow$ Closure & .10 & {$[-.113, .301]$} & .364 \\
\hline \multirow[t]{20}{*}{ Creative Thinking } & Fluency $\rightarrow \mathrm{GO}$ & -.01 & {$[-.211, .214]$} & .956 \\
\hline & Fluency $\rightarrow \mathrm{GA}$ & .05 & {$[-.189, .251]$} & .711 \\
\hline & Fluency $\rightarrow \mathrm{GF}$ & .16 & {$[-.132, .390]$} & .281 \\
\hline & Fluency $\rightarrow \mathrm{GV}$ & .01 & {$[-.214, .241]$} & .977 \\
\hline & Elaboration $\rightarrow \mathrm{GO}$ & -.06 & {$[-.233, .159]$} & .638 \\
\hline & Elaboration $\rightarrow \mathrm{GA}$ & -.02 & {$[-.184,193]$} & .872 \\
\hline & Elaboration $\rightarrow \mathrm{GF}$ & .05 & {$[-.188, .248]$} & .761 \\
\hline & Elaboration $\rightarrow \mathrm{GV}$ & -.11 & {$[-.283, .153]$} & .498 \\
\hline & Originality $\rightarrow \mathrm{GO}$ & .10 & {$[-.123, .341]$} & .411 \\
\hline & Originality $\rightarrow G A$ & -.01 & {$[-.177, .179]$} & .929 \\
\hline & Originality $\rightarrow G F$ & -.05 & {$[-.279, .232]$} & .789 \\
\hline & Originality $\rightarrow \mathrm{GV}$ & .10 & {$[-.156, .376]$} & .426 \\
\hline & Titles $\rightarrow \mathrm{GO}$ & .20 & {$[.028,361]$} & .030 \\
\hline & Titles $\rightarrow \mathrm{GA}$ & .24 & $.016, .435]$ & .029 \\
\hline & Titles $\rightarrow \mathrm{GF}$ & .04 & {$[-.130, .227]$} & .606 \\
\hline & Titles $\rightarrow \mathrm{GV}$ & .17 & {$[.014,324]$} & .033 \\
\hline & Closure $\rightarrow \mathrm{GO}$ & -.12 & {$[-.306, .090]$} & .339 \\
\hline & Closure $\rightarrow \mathrm{GA}$ & -.10 & {$[-.269, .064]$} & .175 \\
\hline & Closure $\rightarrow \mathrm{GF}$ & .05 & {$[-.122,225]$} & .593 \\
\hline \multirow{2}{*}{\multicolumn{5}{|c|}{ Indirect effects }} \\
\hline & & & & \\
\hline \multirow[t]{12}{*}{ Motor Performance } & $\mathrm{COD} \rightarrow \mathrm{GO}$ & -.09 & {$[-.163,-.013]$} & .013 \\
\hline & $\mathrm{COD} \rightarrow \mathrm{GA}$ & -.09 & {$[-.184,-.013]$} & .032 \\
\hline & $\mathrm{COD} \rightarrow \mathrm{GF}$ & -.02 & {$[-.099,-.073]$} & .810 \\
\hline & $\mathrm{COD} \rightarrow \mathrm{GV}$ & -.06 & {$[-.145, .010]$} & .114 \\
\hline & Sprint $\rightarrow \mathrm{GO}$ & -.02 & {$[.190, .147]$} & .442 \\
\hline & Sprint $\rightarrow G A$ & .03 & {$[.102, .127]$} & .290 \\
\hline & Sprint $\rightarrow G F$ & -.06 & {$[.400, .447]$} & .098 \\
\hline & Sprint $\rightarrow$ GV & .01 & {$[-.065, .052]$} & .782 \\
\hline & VJFA $\rightarrow G O$ & .01 & {$[-.053,-.065]$} & .866 \\
\hline & VJFA $\rightarrow G A$ & .02 & {$[-.030, .084]$} & .337 \\
\hline & VJFA $\rightarrow G F$ & .05 & {$[-.072, .068]$} & .985 \\
\hline & VJFA $\rightarrow G V$ & -.01 & {$[-.059, .052]$} & .782 \\
\hline
\end{tabular}

Note. COD = change of direction; VJFA = vertical jump free arms; $\mathrm{GO}=$ game originality; $\mathrm{GA}=$ game attempts; $\mathrm{GF}$ = game fluency; $\mathrm{GV}=$ game versatility; $\beta=$ direct effects; $\mathrm{Cl}-95 \%=$ confidence interval; $p=$ level of significance

and females and younger (6 to 8 years) and older (9 to 10 years) primary school-aged children. Examining the bivariate correlations, several negative (COD and sprint), and positive associations (vertical jump) were displayed between motor skills and all the creative thinking psychometric indicators. The interpretation of the COD and sprint results should consider with caution due to the test score characteristics. Both negative associations mean that short times indicate better performance. Whereas the positive association founded in vertical jump means that a higher jump score reveals
Table 6. Direct and indirect effects of regression analysis among all variables in male samples.

\begin{tabular}{|c|c|c|c|c|}
\hline Predictors & Path & $\beta$ & $\mathrm{Cl}-95 \%$ & $p$ \\
\hline \multicolumn{5}{|l|}{ Direct effects } \\
\hline \multirow[t]{15}{*}{ Motor Performance } & COD $\rightarrow$ Fluency & -.20 & {$[-.507, .184]$} & .333 \\
\hline & $\mathrm{COD} \rightarrow$ Elaboration & -.28 & {$[-.540, .038]$} & .091 \\
\hline & $C O D \rightarrow$ Originality & -.39 & {$[-.645,-.067]$} & .021 \\
\hline & COD $\rightarrow$ Titles & -.51 & {$[-.692-.216]$} & .004 \\
\hline & $\mathrm{COD} \rightarrow$ Closure & .01 & {$[-.319, .277]$} & .954 \\
\hline & Sprint $\rightarrow$ Fluency & -.18 & {$[-.461, .099]$} & .189 \\
\hline & Sprint $\rightarrow$ Elaboration & .20 & {$[-.100, .411]$} & .152 \\
\hline & Sprint $\rightarrow$ Originality & -.04 & {$[-.347, .203]$} & .662 \\
\hline & Sprint $\rightarrow$ Titles & .07 & {$[-.224,226]$} & .593 \\
\hline & Sprint $\rightarrow$ Closure & -.09 & {$[-.421, .226]$} & .531 \\
\hline & VJFA $\rightarrow$ Fluency & -.15 & {$[-.374, .200]$} & .412 \\
\hline & VJFA $\rightarrow$ Elaboration & .22 & {$[-.075, .525]$} & .141 \\
\hline & VJFA $\rightarrow$ Originality & -.05 & {$[-.299, .249]$} & .807 \\
\hline & VJFA $\rightarrow$ Titles & -.02 & {$[-.215, .271]$} & .938 \\
\hline & VJFA $\rightarrow$ Closure & .15 & {$[-.170, .449]$} & .370 \\
\hline \multirow[t]{20}{*}{ Creative Thinking } & Fluency $\rightarrow \mathrm{GO}$ & .10 & {$[-.171, .383]$} & .476 \\
\hline & Fluency $\rightarrow \mathrm{GA}$ & .12 & {$[-.179, .358]$} & .399 \\
\hline & Fluency $\rightarrow \mathrm{GF}$ & .26 & {$[-.086, .560]$} & .127 \\
\hline & Fluency $\rightarrow \mathrm{GV}$ & .08 & {$[-.253, .355]$} & .656 \\
\hline & Elaboration $\rightarrow \mathrm{GO}$ & -.05 & {$[-.268, .241]$} & .748 \\
\hline & Elaboration $\rightarrow \mathrm{GA}$ & -.09 & {$[-.286, .179]$} & .469 \\
\hline & Elaboration $\rightarrow \mathrm{GF}$ & .11 & {$[-.217, .379]$} & .542 \\
\hline & Elaboration $\rightarrow \mathrm{GV}$ & -.14 & {$[-.382, .200]$} & .465 \\
\hline & Originality $\rightarrow \mathrm{GO}$ & -.04 & {$[-.400, .343]$} & .820 \\
\hline & Originality $\rightarrow G A$ & -.14 & {$[-.403, .163]$} & .303 \\
\hline & Originality $\rightarrow \mathrm{GF}$ & -.04 & {$[-.395, .358]$} & .873 \\
\hline & Originality $\rightarrow \mathrm{GV}$ & .05 & {$[-.369, .475]$} & .796 \\
\hline & Titles $\rightarrow \mathrm{GO}$ & .27 & {$[.001, .473]$} & .049 \\
\hline & Titles $\rightarrow \mathrm{GA}$ & .34 & {$[-.049, .632]$} & .083 \\
\hline & Titles $\rightarrow$ GF & -.09 & {$[-.331, .139]$} & .432 \\
\hline & Titles $\rightarrow \mathrm{GV}$ & .18 & {$[-.047, .397]$} & .125 \\
\hline & Closure $\rightarrow \mathrm{GO}$ & -.08 & {$[-.339, .187]$} & .558 \\
\hline & Closure $\rightarrow \mathrm{GA}$ & -.05 & {$[-.268, .183]$} & .604 \\
\hline & Closure $\rightarrow \mathrm{GF}$ & .01 & {$[-.189, .253]$} & .907 \\
\hline \multirow{2}{*}{\multicolumn{5}{|c|}{ Indirect effects }} \\
\hline & & & & \\
\hline \multirow[t]{12}{*}{ Motor Performance } & $\mathrm{COD} \rightarrow \mathrm{GO}$ & -.12 & {$[-.271,-.001]$} & .048 \\
\hline & $\mathrm{COD} \rightarrow \mathrm{GA}$ & -.12 & {$[-.301, .011]$} & .068 \\
\hline & $\mathrm{COD} \rightarrow \mathrm{GF}$ & -.02 & {$[-.186, .153]$} & .864 \\
\hline & $\mathrm{COD} \rightarrow \mathrm{GV}$ & -.08 & {$[-.223, .032]$} & .189 \\
\hline & Sprint $\rightarrow \mathrm{GO}$ & -.01 & {$[-.105, .085]$} & .892 \\
\hline & Sprint $\rightarrow G A$ & -.01 & {$[-.115, .095]$} & .934 \\
\hline & Sprint $\rightarrow G F$ & -.03 & {$[-.170, .067]$} & .371 \\
\hline & Sprint $\rightarrow \mathrm{GV}$ & -.03 & {$[-.141, .065]$} & .413 \\
\hline & VJFA $\rightarrow G O$ & -.04 & {$[-.156, .089]$} & .457 \\
\hline & VJFA $\rightarrow G A$ & -.04 & {$[-.174, .079]$} & .459 \\
\hline & VJFA $\rightarrow \mathrm{GF}$ & -.01 & {$[-.150, .157]$} & .858 \\
\hline & VJFA $\rightarrow G V$ & -.05 & {$[-.146, .063]$} & .290 \\
\hline
\end{tabular}

Note. COD $=$ change of direction; VJFA $=$ vertical jump free arms; $\mathrm{GO}=$ game originality; $\mathrm{GA}=$ game attempts; $\mathrm{GF}=$ game fluency; $\mathrm{GV}=$ game versatility; $\beta=$ direct effects; $\mathrm{Cl}-95 \%=$ confidence interval; $p=$ level of significance

a better performance. These findings have been supported by a few studies (Campos, 2014; Latorre Román et al., 2017; Lupu, 2012; Tekin \& Güllü, 2010). Although different motor tests were performed the results are aligned to those of Latorre Román et al. (2017) once aerobic capacity, leg strength, and sprint were correlated with whole creative thinking in primary school-aged children. As regards to the handgrip strength, no association was identified.

On the other hand, to identify eventual commonalities between creative thinking and sports creativity it 
Table 7. Direct and indirect effects of regression analysis among all variables in female sample.

\begin{tabular}{|c|c|c|c|c|}
\hline Predictors & Path & $\beta$ & $\mathrm{Cl}-95 \%$ & $p$ \\
\hline \multicolumn{5}{|l|}{ Direct effects } \\
\hline \multirow[t]{15}{*}{ Motor Performance } & COD $\rightarrow$ Fluency & .13 & {$[-.158, .343]$} & .343 \\
\hline & COD $\rightarrow$ Elaboration & -.32 & {$[-.520,-.068]$} & .011 \\
\hline & $C O D \rightarrow$ Originality & .10 & {$[-.148, .314]$} & .394 \\
\hline & COD $\rightarrow$ Titles & -.21 & {$[-.429, .016]$} & .072 \\
\hline & $\mathrm{COD} \rightarrow$ Closure & .16 & {$[-.098, .353]$} & .201 \\
\hline & Sprint $\rightarrow$ Fluency & -.53 & {$[-.703,-.275]$} & .002 \\
\hline & Sprint $\rightarrow$ Elaboration & -.14 & {$[-.392, .163]$} & .334 \\
\hline & Sprint $\rightarrow$ Originality & -.50 & {$[-.650,-.287]$} & .001 \\
\hline & Sprint $\rightarrow$ Titles & .03 & {$[-.196,281]$} & .847 \\
\hline & Sprint $\rightarrow$ Closure & -.57 & {$[-.748,-.261]$} & .004 \\
\hline & VJFA $\rightarrow$ Fluency & -.05 & {$[-.274, .168]$} & .599 \\
\hline & VJFA $\rightarrow$ Elaboration & .07 & {$[-.150, .304]$} & .569 \\
\hline & VJFA $\rightarrow$ Originality & -.14 & {$[-.344, .082]$} & .218 \\
\hline & VJFA $\rightarrow$ Titles & .31 & {$[.054, .531]$} & .022 \\
\hline & VJFA $\rightarrow$ Closure & .12 & {$[-.122,340]$} & .360 \\
\hline \multirow{20}{*}{ Creative Thinking } & Fluency $\rightarrow \mathrm{GO}$ & -.18 & {$[-.408, .178]$} & .360 \\
\hline & Fluency $\rightarrow \mathrm{GA}$ & -.04 & {$[-.483, .343]$} & .854 \\
\hline & Fluency $\rightarrow$ GF & .08 & {$[-.230, .400]$} & .539 \\
\hline & Fluency $\rightarrow$ GV & .01 & {$[-.240, .378]$} & .899 \\
\hline & Elaboration $\rightarrow \mathrm{GO}$ & .13 & {$[-.338, .465]$} & .741 \\
\hline & Elaboration $\rightarrow \mathrm{GA}$ & .27 & {$[.012, .514]$} & .038 \\
\hline & Elaboration $\rightarrow \mathrm{GF}$ & -.08 & {$[-.320, .153]$} & .512 \\
\hline & Elaboration $\rightarrow \mathrm{GV}$ & .12 & {$[-.244, .515]$} & .592 \\
\hline & Originality $\rightarrow \mathrm{GO}$ & .06 & {$[-.128, .214]$} & .470 \\
\hline & Originality $\rightarrow G A$ & -.05 & {$[-.425, .435]$} & .926 \\
\hline & Originality $\rightarrow \mathrm{GF}$ & -.16 & {$[-.484,247]$} & .444 \\
\hline & Originality $\rightarrow G V$ & -.16 & {$[-.437, .043]$} & .144 \\
\hline & Titles $\rightarrow \mathrm{GO}$ & .09 & {$[-.195, .373]$} & .707 \\
\hline & Titles $\rightarrow \mathrm{GA}$ & .03 & {$[-.254,276]$} & .850 \\
\hline & Titles $\rightarrow \mathrm{GF}$ & .22 & {$[-.091, .461]$} & .150 \\
\hline & Titles $\rightarrow$ GV & .11 & {$[-.244, .406]$} & .579 \\
\hline & Closure $\rightarrow \mathrm{GO}$ & .03 & {$[-.121, .168]$} & .638 \\
\hline & Closure $\rightarrow \mathrm{GA}$ & -.02 & {$[-.282, .227]$} & .871 \\
\hline & Closure $\rightarrow \mathrm{GF}$ & .39 & {$[.172, .624]$} & .002 \\
\hline & Closure $\rightarrow$ RV & -.09 & {$[-.324, .114]$} & .342 \\
\hline \multicolumn{5}{|l|}{ Indirect effects } \\
\hline \multirow{12}{*}{ Motor Performance } & $\mathrm{COD} \rightarrow \mathrm{GO}$ & -.07 & {$[-.187, .024]$} & .149 \\
\hline & $\mathrm{COD} \rightarrow \mathrm{GA}$ & -.11 & {$[-.236, .006]$} & .059 \\
\hline & $\mathrm{COD} \rightarrow \mathrm{GF}$ & -.04 & {$[-.068, .172]$} & .349 \\
\hline & $\mathrm{COD} \rightarrow \mathrm{GV}$ & -.09 & {$[-.218, .022]$} & .128 \\
\hline & Sprint $\rightarrow \mathrm{GO}$ & .03 & {$[-.090, .134]$} & .719 \\
\hline & Sprint $\rightarrow G A$ & .02 & {$[-.120, .174]$} & .765 \\
\hline & Sprint $\rightarrow$ GF & -.17 & {$[-.341,-.008]$} & .040 \\
\hline & Sprint $\rightarrow$ GV & .12 & {$[-.041, .269]$} & .161 \\
\hline & VJFA $\rightarrow G O$ & .04 & {$[-.054, .140]$} & .421 \\
\hline & VJFA $\rightarrow$ GA & .03 & {$[-.049, .155]$} & .323 \\
\hline & VJFA $\rightarrow$ GF & .12 & {$[.006, .256]$} & .037 \\
\hline & VJFA $\rightarrow G V$ & .05 & {$[-.054, .162]$} & .317 \\
\hline
\end{tabular}

Note. COD = change of direction; VJFA = vertical jump free arms; $\mathrm{GO}$ = game originality; $\mathrm{GA}=$ game attempts; $\mathrm{GF}=$ game fluency; $\mathrm{GV}=$ game versatility; $\beta=$ direct effects; $\mathrm{R} 2$ = variance explained; $\mathrm{Cl}-$ $95 \%=$ confidence interval; $p=$ level of significance.

was estimated the linear relationship by computing bivariate correlations between TTCT and CBATS dimensions. The TTCT and sports creativity shared two common dimensions, namely fluency and originality. Nevertheless, only fluency showed a positive association between both thinking and in-game creativity tests. Fluency is the ability to produce a number of relevant ideas (Kim, 2006, 2011) and demonstrated an association with game fluency, which represents the ability to perform as many effective movement/technical actions as possible (Santos et al., 2017). These
Table 8. Direct and indirect effects of regression analysis among all variables in younger samples (6 to 8 years old).

\begin{tabular}{|c|c|c|c|c|}
\hline Predictors & Path & $\beta$ & $\mathrm{Cl}-95 \%$ & $p$ \\
\hline \multicolumn{5}{|l|}{ Direct effects } \\
\hline \multirow[t]{15}{*}{ Motor Performance } & COD $\rightarrow$ Fluency & .06 & {$[-.196,280]$} & .570 \\
\hline & $\mathrm{COD} \rightarrow$ Elaboration & -.22 & {$[-.436, .082]$} & .143 \\
\hline & $C O D \rightarrow$ Originality & -.04 & {$[-.294, .082]$} & .715 \\
\hline & COD $\rightarrow$ Titles & -.27 & {$[-.503,-.045]$} & .019 \\
\hline & COD $\rightarrow$ Closure & .15 & {$[-.068, .342]$} & .200 \\
\hline & Sprint $\rightarrow$ Fluency & -.47 & {$[-.648,-.216]$} & .002 \\
\hline & Sprint $\rightarrow$ Elaboration & .04 & {$[-.193, .262]$} & .748 \\
\hline & Sprint $\rightarrow$ Originality & -.40 & {$[-.580,-.147]$} & .002 \\
\hline & Sprint $\rightarrow$ Titles & .05 & {$[-.158,244]$} & .655 \\
\hline & Sprint $\rightarrow$ Closure & -.41 & {$[-.636,-.110]$} & .008 \\
\hline & VJFA $\rightarrow$ Fluency & -.12 & {$[-.232, .140]$} & .318 \\
\hline & VJFA $\rightarrow$ Elaboration & .09 & {$[-.150, .346]$} & .514 \\
\hline & VJFA $\rightarrow$ Originality & -.14 & {$[-.340, .097]$} & .259 \\
\hline & VJFA $\rightarrow$ Titles & .20 & {$[-.032, .424]$} & .088 \\
\hline & VJFA $\rightarrow$ Closure & .03 & {$[-.214,290]$} & .796 \\
\hline \multirow[t]{20}{*}{ Creative Thinking } & Fluency $\rightarrow \mathrm{GO}$ & -.12 & {$[-.399, .183]$} & .454 \\
\hline & Fluency $\rightarrow \mathrm{GA}$ & -.14 & {$[-.393,178]$} & .392 \\
\hline & Fluency $\rightarrow$ GF & .19 & {$[-.162, .482]$} & .311 \\
\hline & Fluency $\rightarrow \mathrm{GV}$ & -.09 & {$[-.378,199]$} & .606 \\
\hline & Elaboration $\rightarrow \mathrm{GO}$ & -.15 & {$[-.278,059]$} & .116 \\
\hline & Elaboration $\rightarrow \mathrm{GA}$ & -.06 & {$[-.274,199]$} & .622 \\
\hline & Elaboration $\rightarrow \mathrm{GF}$ & -.02 & {$[-.259, .213]$} & .843 \\
\hline & Elaboration $\rightarrow \mathrm{GV}$ & -.20 & {$[-.324,-.040]$} & .021 \\
\hline & Originality $\rightarrow \mathrm{GO}$ & .14 & {$[-.176, .514]$} & .510 \\
\hline & Originality $\rightarrow G A$ & .09 & {$[-.175, .345]$} & .543 \\
\hline & Originality $\rightarrow G F$ & -.10 & {$[-.382,200]$} & .451 \\
\hline & Originality $\rightarrow \mathrm{GV}$ & .07 & {$[-.250, .403]$} & .734 \\
\hline & Titles $\rightarrow \mathrm{GO}$ & .19 & {$[-.050, .358]$} & .126 \\
\hline & Titles $\rightarrow \mathrm{GA}$ & .22 & {$[-.028, .470]$} & .088 \\
\hline & Titles $\rightarrow \mathrm{GF}$ & -.10 & {$[-.291, .126]$} & .408 \\
\hline & Titles $\rightarrow \mathrm{GV}$ & .26 & {$[.033, .482]$} & .024 \\
\hline & Closure $\rightarrow \mathrm{GO}$ & -.06 & {$[-.230, .164]$} & .573 \\
\hline & Closure $\rightarrow \mathrm{GA}$ & -.03 & {$[-.257, .193]$} & .724 \\
\hline & Closure $\rightarrow \mathrm{GF}$ & .08 & {$[-.187, .318]$} & .580 \\
\hline & Closure $\rightarrow \mathrm{RV}$ & -.01 & {$[-.187, .156]$} & .910 \\
\hline \multicolumn{5}{|l|}{ Indirect effects } \\
\hline \multirow[t]{12}{*}{ Motor Performance } & $\mathrm{COD} \rightarrow \mathrm{GO}$ & -.04 & {$[-.147, .045]$} & .365 \\
\hline & $\mathrm{COD} \rightarrow \mathrm{GA}$ & -.06 & {$[-.210, .039]$} & .236 \\
\hline & $\mathrm{COD} \rightarrow \mathrm{GF}$ & .06 & {$[-.006, .145]$} & .073 \\
\hline & $\mathrm{COD} \rightarrow \mathrm{GV}$ & -.04 & {$[-.156, .065]$} & .489 \\
\hline & Sprint $\rightarrow \mathrm{GO}$ & .03 & {$[-.063, .119]$} & .526 \\
\hline & Sprint $\rightarrow G A$ & .05 & {$[-.039, .168]$} & .244 \\
\hline & Sprint $\rightarrow \mathrm{GF}$ & -.08 & {$[-.237, .015]$} & .086 \\
\hline & Sprint $\rightarrow$ GV & .02 & {$[-.075, .137]$} & .708 \\
\hline & VJFA $\rightarrow G O$ & .02 & {$[-.063, .083]$} & .690 \\
\hline & VJFA $\rightarrow G A$ & .04 & {$[-.034, .127]$} & .271 \\
\hline & VJFA $\rightarrow \mathrm{GF}$ & -.03 & {$[-.124,039]$} & .321 \\
\hline & VJFA $\rightarrow$ GV & .04 & {$[-.039, .118]$} & .409 \\
\hline
\end{tabular}

Note. $\mathrm{COD}=$ change of direction; VJFA $=$ vertical jump free arms; $\mathrm{GO}=$ game originality; $\mathrm{GA}=$ game attempts; $\mathrm{GF}=$ game fluency; $\mathrm{GV}=$ game versatility; $\beta=$ direct effects; $\mathrm{R} 2=$ variance explained; $\mathrm{Cl}-$ $95 \%=$ confidence interval; $p=$ level of significance.

results revealed a potential interplay between similar cognitive and motor components (Richard et al., 2018; Santos et al., 2017). Alike, results were found in Scibinetti Tocci and Pesce study (2011) since emerged a significant positive association between creative thinking and motor creativity in two common dimensions, namely fluencies, and flexibilities.

To counteract the fourth-grade slump is valuable a better understating of the underlying predictors related to creative thoughts ideation. In this vein, to analyze the predictive value of physical fitness and creative thinking 
Table 9. Direct and indirect effects of regression analysis among all variables in older samples ( 9 to 10 years old).

\begin{tabular}{|c|c|c|c|c|}
\hline Predictors & Path & $\beta$ & $\mathrm{Cl}-95 \%$ & $p$ \\
\hline \multicolumn{5}{|l|}{ Direct effects } \\
\hline \multirow[t]{15}{*}{ Motor Performance } & COD $\rightarrow$ Fluency & .05 & {$[-.355, .401]$} & .768 \\
\hline & COD $\rightarrow$ Elaboration & -.18 & {$[-.501, .213]$} & .389 \\
\hline & $C O D \rightarrow$ Originality & -.34 & {$[-.616, .213]$} & .109 \\
\hline & COD $\rightarrow$ Titles & -.19 & {$[-.483,228]$} & .346 \\
\hline & $\mathrm{COD} \rightarrow$ Closure & .42 & {$[.195, .595]$} & .004 \\
\hline & Sprint $\rightarrow$ Fluency & -.01 & {$[-377.324]$} & .923 \\
\hline & Sprint $\rightarrow$ Elaboration & -.05 & {$[-.345,344]$} & .812 \\
\hline & Sprint $\rightarrow$ Oriqinality & .04 & {$[-.318, .411]$} & .889 \\
\hline & Sprint $\rightarrow$ Titles & .02 & {$[-.260, .375]$} & .839 \\
\hline & Sprint $\rightarrow$ Closure & -.08 & {$[-.352, .334]$} & .676 \\
\hline & VJFA $\rightarrow$ Fluency & -.07 & {$[-.385, .255]$} & .728 \\
\hline & VJFA $\rightarrow$ Elaboration & .10 & {$[-.213, .255]$} & .552 \\
\hline & VJFA $\rightarrow$ Originality & -.05 & {$[-.345, .282]$} & .806 \\
\hline & VJFA $\rightarrow$ Titles & .04 & {$[-.246, .362]$} & .806 \\
\hline & VJFA $\rightarrow$ Closure & .25 & {$[.002 .486]$} & .046 \\
\hline \multirow[t]{20}{*}{ Creative Thinking } & Fluency $\rightarrow \mathrm{GO}$ & .06 & {$[-.189, .327]$} & .637 \\
\hline & Fluency $\rightarrow \mathrm{GA}$ & .21 & {$[-.057, .446]$} & .131 \\
\hline & Fluency $\rightarrow \mathrm{GF}$ & .03 & {$[-.340, .446]$} & .858 \\
\hline & Fluency $\rightarrow \mathrm{GV}$ & .06 & {$[-.203, .338]$} & .659 \\
\hline & Elaboration $\rightarrow \mathrm{GO}$ & .06 & {$[-.260, .384]$} & .733 \\
\hline & Elaboration $\rightarrow \mathrm{GA}$ & .05 & {$[-.225,369]$} & .798 \\
\hline & Elaboration $\rightarrow \mathrm{GF}$ & .14 & {$[-.245, .437]$} & .534 \\
\hline & Elaboration $\rightarrow \mathrm{GV}$ & .03 & {$[-.340, .422]$} & .816 \\
\hline & Originality $\rightarrow \mathrm{GO}$ & .04 & {$[-.232,342]$} & .767 \\
\hline & Originality $\rightarrow G A$ & -.09 & {$[-.324 .229]$} & .513 \\
\hline & Originality $\rightarrow \mathrm{GF}$ & -.05 & {$[-.408, .374]$} & .809 \\
\hline & Originality $\rightarrow \mathrm{GV}$ & .13 & {$[-.289,483]$} & .571 \\
\hline & Titles $\rightarrow \mathrm{GO}$ & .09 & {$[-.258, .346]$} & .675 \\
\hline & Titles $\rightarrow \mathrm{GA}$ & .25 & {$[-.096, .527]$} & .234 \\
\hline & Titles $\rightarrow \mathrm{GF}$ & -.16 & {$[-.412, .119]$} & .271 \\
\hline & Titles $\rightarrow \mathrm{GV}$ & -.04 & {$[-.284 .208]$} & .670 \\
\hline & Closure $\rightarrow \mathrm{GO}$ & -.22 & {$[-.595, .181]$} & .305 \\
\hline & Closure $\rightarrow \mathrm{GA}$ & -.10 & {$[-.322,195]$} & .436 \\
\hline & Closure $\rightarrow \mathrm{GF}$ & -.22 & {$[-.400-.012]$} & .049 \\
\hline & Closure $\rightarrow \mathrm{RV}$ & -.21 & {$[-.555 .173]$} & 298 \\
\hline \multicolumn{5}{|l|}{ Indirect effects } \\
\hline \multirow[t]{12}{*}{ Motor Performance } & $\mathrm{COD} \rightarrow \mathrm{GO}$ & -.13 & {$[-.361, .023]$} & .125 \\
\hline & $\mathrm{COD} \rightarrow \mathrm{GA}$ & -.06 & {$[-.207, .079]$} & .410 \\
\hline & $\mathrm{COD} \rightarrow \mathrm{GF}$ & -.07 & {$[-.253, .184]$} & .746 \\
\hline & $\mathrm{COD} \rightarrow \mathrm{GV}$ & -.13 & {$[-.323, .036]$} & .139 \\
\hline & Sprint $\rightarrow G O$ & .02 & {$[-.095, .171]$} & .614 \\
\hline & Sprint $\rightarrow G A$ & .01 & {$[-.090, .002]$} & .501 \\
\hline & Sprint $\rightarrow \mathrm{GF}$ & .01 & {$[-.177, .127]$} & .977 \\
\hline & Sprint $\rightarrow G V$ & .02 & {$[-.113, .159]$} & .681 \\
\hline & VJFA $\rightarrow \mathrm{GO}$ & -.05 & {$[-.193, .078]$} & .444 \\
\hline & $\mathrm{VJFA} \rightarrow \mathrm{GA}$ & -.02 & {$[-.138, .121]$} & .953 \\
\hline & VJFA $\rightarrow \mathrm{GF}$ & -.05 & {$[-.175 . .110]$} & .623 \\
\hline & $\mathrm{VJFA} \rightarrow \mathrm{GV}$ & -.06 & {$[-.224, .059]$} & .239 \\
\hline
\end{tabular}

Note. COD = change of direction; VJFA = vertical jump free arms; $\mathrm{GO}$ = game originality; $\mathrm{GA}=$ game attempts; $\mathrm{GF}=$ game fluency; $\mathrm{GV}=$ game versatility; $\beta=$ direct effects; $\mathrm{R} 2$ = variance explained; $\mathrm{Cl}-$ $95 \%=$ confidence interval; $p=$ level of significance.

in game creativity the variables were under a regression analysis. The logic of this heuristic hierarchical model distinguished between the impact of more proximal variables represented by motor skills paralleling to creative thinking and more distal factors represented by in-game creativity. This structure was adopted since the present study was intended to reinforce the current knowledge considering the motor and thinking creative abilities, highlighted in previous studies and add new insights into the relationship between creative thinking and sports creativity. Indeed, not many studies have tested the relationship between physical fitness or motor skills and creative thinking (Latorre Román et al., 2017). However, in order to avoid the creativity measurements as the whole construct, this study focused on the analysis of particular creative thinking indicators. Speed-powerrelated abilities such as $15 \mathrm{~m}$ straight sprint and T-test COD protocol demonstrated equally important to predict all creative thinking psychometric indicators such as: fluency, closure and originality; and titles and elaboration, respectively. Interestingly, studies demonstrated that both tests are moderately correlated with each other (Sassi et al., 2009) and correlated with aerobic capacity (Gibson, Currie, Hohnston \& Hill, 2013), which possibly explains, in part, the results achieved. Aerobic capacity has been put forth as an indicator of creativity and predictor of cognitive functioning (Alvarez-Bueno et al., 2017; Blanchette et al., 2005; Hillman et al., 2005; Latorre Román et al., 2017). It seems that more static and isolated tests, such as handgrip strength and vertical jump do not consistently predict thinking abilities compared to more compound skills (e.g., COD). Notwithstanding, achieving adequate motor skills during childhood may be essential in the development of creative thoughts. Considering a gender analysis, the previous motor skills are consistent to predict several creative thinking components, namely the original solutions. This is the ability to produce unusual, unexpected, and novel ideas (Kim, 2011), since emerged as a common component in both male and female. While a better performance on COD predicts higher scores on titles in males, in its turn, the COD is related to the elaboration in females. In spite of the results of the few studies undertaken on gender differences in creative thinking are contradictory, there is no clear finding surrounding this domain. Hence, further studies are highly recommended to provide further insights. Otherwise, few studies have investigated whether physical fitness or motor performance and creative thinking in childhood may be influenced by age-related stages (Domínguez et al., 2015; Gaul \& Issartel, 2016; Runco, 2014). In younger children, the COD and sprint predicted the originality, titles, fluency, and closure, whereas in older, only predicted the closure. Motor skills revealed more sensitive in predicting thinking abilities in children aged 6 to 8 years. In fact, studies on motor competence suggested that in this period the children are going through a substantial evolving in their fine and motor development, which seems to occur in parallel with the development of specific cognitive skills (Gaul \& Issartel, 2016; Pagona \& Costas, 2008; Wassenberg et al., 2005). Concomitantly, these findings seem aligned with the vision of younger children are usually more flexible and imaginative in the production of unusual and novel thoughts and keep a high degree of abstraction and open mind while processing information (Latorre Román et al., 
2017; Lupu, 2012). These preliminary results claimed that physical fitness influences several key psychometric indicators of creative thoughts mainly in early years since during this period does not prevail a pressure to a conformity and to provide responses that meet social norms (Richard et al., 2018). However, more scientific evidence is needed to strengthen the previous findings. These results could convey interesting contributions to better frame the fourth grade slump. In this vein, a better understanding of the impact of physical fitness underlying this higher-order disposition could facilitate the planning of training interventions intended to ignite creative thinking in primary school-aged children and, thereby, mitigate the effects of this slump.

Considering the indirect effects of motor skills on sports creativity, the COD emerged as a reliable indicator to predict the attempts and originality in game settings. As alluded to, in the T-test children perform runs with different modes of travel (e.g., lateral shuffling and backpedaling) in a "T-shape" course (Sassi et al., 2009). In team sports, children are required to accelerate, decelerate, run at different speeds, and change direction considering distinct angles to cope with the game demands (Coutinho et al., 2018; Memmert, 2015; Sassi et al., 2009). It seems that children who are able to perform complex motor actions within motion approach sports games challenge more easily (Memmert et al., 2010; Santos et al., 2016). In this line of reasoning is important to note, that children from the present study gathered few previous experiences in unstructured and structured sports at clubs, even as constantly participated in physical education lessons. According to several studies, these previous experiences in sports, enhance children motor repertoire which possibly impacts their sports creativity (Lupu, 2012; Memmert, 2015; Memmert et al., 2010; Pesce et al., 2019, 2016; Tekin \& Güllü, 2010). Interestingly, common trends were observed considering the previous results between motor skills and creative thinking, since COD remained as a reliable predictor of thinking and game originalities in male, instead sprint predicted the thinking and game fluencies in female. Possibly, the largest number of hours accumulated in structured and unstructured practice by males may convey them to display more often novel behaviors in the field. These results provide further insights in a potential interplay between motor performance, creative thinking, and sports creativity. Inversely, no standardized indirect effects between motor performance and game creativity were founded considering distinct age-groups.
Yet, to our knowledge, no studies have ever examined the impact of creative thinking on sports creativity. The present results across thinking variables demonstrated several direct predictors between specific psychometric indicators of creative thinking and in-game creative components. These results reinforce the statements provided by Campos (2014) which refers that is relevant to train the 'bodymind' to enact new possibilities instantaneously to solve sports emerging problems. Given that, titles emerged as a key component whereas predicting the game attempts, versatility, and originality. This component expresses the degree beyond concrete labeling based on the idea that creativity requires an abstraction of thought (Kim, 2006, 2011). The previous thinking component is related to the sports disposition to produce nonstandard actions such as to perform novel and original forms to pass, dribble, or shoot in game situations (Coutinho et al., 2018; Santos et al., 2018, 2016). Titles seem to ignite the children's personal creativity type since attempts, versatility, and originality are aligned with this creativity expression, which in turn, is related to the discovery of new solutions that allows to overcome personal limitations (Boden, 1996). Interestingly, the thinking component most stressed by the Skills4Genius program was also the titles supporting that this component is sensitive to the effects of a sports creativity-based program (Santos et al., 2017), for instance, this study also identified an association between thinking and team sports creativity. Titles is the only written psychometric indicator while the remaining four (fluency, elaboration, originality, and closure) gauges figurative creativity. In this vein, Latorre Román results (2017) revealed higher values in verbal creativity rather than figurative creativity in primary school children. Inversely, research demonstrated that children expression through drawings reaches their peak at 10-14 years, at the end of this period, verbal creativity proficiency is higher due to the fact that becomes the most used way of sharing ideas (for refs Dău-Gaşpar, 2013). Results on gender differences suggested that males maintained the previous trends with titles as a predictor of game originality, whereas females displayed distinct figurative predictors such as thinking elaboration and game attempt as well as thinking closure and game fluency. These findings possibly revealed differences in specific creative thinking processes according to gender (Prieto et al., 2006). Similar to previous analysis on motor skills, creative thinking revealed less sensitivity in predicting game creative behaviors mainly in older children. Further research is necessary to gain insight to better understand if this dynamic progress with age until adulthood.

One of the strengths of this study is that it represents a pioneering contribution to this area of research. Apart 
from, this study had a few limitations that should be acknowledged in future works. For instance, the findings cannot be generalized for populations of all ages. Besides, the methodological diversity across the available studies with regard to creativity assessment is broad which relies on concerns about whether we were actually assessing the same constructs and processes. Future research should investigate the associations uncovered between motor, thinking, and game predictors in more detail and explore the direct influence of physical fitness on sports creativity as well as the reverse considering different age groups and gender. In conclusion, the findings suggested that there are commonalities in the processes responsible for generating movements and creative thoughts supporting the view of creativity as a general domain as well as an interplay between motor performance, creative thinking, and sports creativity. Notwithstanding, achieving adequate motor skills during childhood may be essential in the development of creative thoughts and sports creativity. In this vein, physical activity and sports creativity-based programs should be included and have more expression in primary schools curricula in order to develop the children's cognitive and sports creativity. This knowledge will assist teachers, coaches, and sports scientists in terms of guidance to develop more effective enrichment environments to improve children's creativity.

\section{Acknowledgments}

The authors would like to express their heartfelt appreciation to all primary schools that participated in this study. In addition, this work was supported in part by the Calouste Gulbenkian Foundation within the Gulbenkian Program for Knowledge.

\section{Disclosure statement}

No potential conflict of interest was reported by the authors.

\section{Funding}

This work was supported by Gulbenkian Academies for Knowledge within the Calouste Gulbenkian Foundation.

\section{ORCID}

Sara Santos (D) http://orcid.org/0000-0002-4090-5790 Diogo Monteiro (iD http://orcid.org/0000-0002-7179-6814

\section{References}

Aguiar, M., Goncalves, B., Botelho, G., Lemmink, K., \& Sampaio, J. (2015). Footballers' movement behaviour during 2-, 3-, 4- and 5-a-side small-sided games. Journal of Sports Sciences, 33(12), 1259-1266. doi:10.1080/ 02640414.2015.1022571

Akoglu, H. (2018). User's guide to correlation coefficients. Turkish Journal of Emergency Medicine, 18(3), 91-93. doi:10.1016/j.tjem.2018.08.001

Alvarez-Bueno, C., Pesce, C., Cavero-Redondo, I., SanchezLopez, M., Martinez-Hortelano, J. A., \& MartinezVizcaino, V. (2017). The effect of physical activity interventions on children's cognition and metacognition: A systematic review and meta-analysis. Journal of the American Academy of Child and Adolescent Psychiatry, 56 (9), 729-738. doi:10.1016/j.jaac.2017.06.012

Blanchette, D. M., Ramocki, S. P., O’Del, J. N., \& Casey, M. S. (2005). Aerobic exercise and creative potential: Immediate and residual effects. Creativity Research Journal, 17(2-3), 257-264. doi:10.1080/10400419.2005.9651483

Boden, M. A. (1996). Dimensions of creativity. Cambridge, CA: MIT Press.

Bournelli, P., Makri, A., \& Mylonas, K. (2009). Motor creativity and self-concept. Creativity Research Journal, 21(1), 104-110. doi:10.1080/10400410802633657

Bowers, M. T., Green, B. C., Hemme, F., \& Chalip, L. (2014). Assessing the relationship between youth sport participation settings and creativity in adulthood. Creativity Research Journal, 26(3), 314-327. doi:10.1080/10400419.2014.929420

Campos, D. (2014). On creativity in sporting activity: With some consequences for education. Fair Play. Revista de Filosofía, Ética y Derecho del Deporte, 2, 52-80.

Cham, H., Reshetnyak, E., Rosenfeld, B., \& Breitbart, W. (2017). Full information maximum likelihood estimation for latent variable interactions with incomplete indicators. Multivariate Behavioral Research, 52(1), 12-30. doi:10.1080/00273171.2016.1245600

Cohen, J. (2013). Statistical power analysis for the behavioral sciences. New York: Academic press.

Colzato, L., Szapora, A., Pannekoek, J. N., \& Hommel, B. (2013). The impact of physical exercise on convergent and divergent thinking. Frontiers Human Neuroscience, 7, 824. doi:10.3389/fnhum.2013.00824

Coutinho, D., Santos, S., Gonçalves, B., Travassos, B., Wong, D. P., Schöllhorn, W., \& Sampaio, J. (2018). The effects of an enrichment training program for youth football attackers. PLoS One, 13(6), e0199008. doi:10.1371/ journal.pone.0199008

Cramond, B., Matthews-Morgan, J., Bandalos, D., \& Zuo, L. (2005). A report on the 40-year follow-up of the torrance tests of creative thinking: Alive and well in the new millennium. Gifted Child Quarterly, 49(4), 283-291. doi:10.1177/001698620504900402

Cropley, A. (2006). In praise of convergent thinking. Creativity Research Journal, 18(3), 391-404. doi:10.1207/ s15326934crj1803_13

Dău-Gaşpar, O. (2013). Verbal and figural creativity in contemporary high-school students. Procedia-Social and Behavioral Sciences, 78, 662-666. doi:10.1016/j. sbspro.2013.04.371 
Dennis, D. J. (2019). SPSS data analysis for univariate, bivariate, and multivariate statistics. Wiley (1st ed.). Hoboken, NJ .ISBN: 9781119465812.

Domínguez, A., Díaz-Pereira, M. P., \& Martínez-Vidal, A. (2015). The evolution of motor creativity during primary education. Journal of Human Sport and Exercise, 10(2), 583-589. doi:10.14198/jhse.2015.102.05

Faul, F., Erdfelder, E., Buchner, A., \& Lang, A.-G. (2009). Statistical power analyses using $G^{\star}$ Power 3.1: Tests for correlation and regression analyses. Behavior Research Methods, 41(4), 1149-1160. doi:10.3758/BRM.41.4.1149

Gaul, D., \& Issartel, J. (2016). Fine motor skill proficiency in typically developing children: On or off the maturation track? Human Movement Science, 46, 78-85. doi:10.1016/ j.humov.2015.12.011

Gibson, N., Currie, J.,Johnston, R. \& Hill, J. (2013). Relationship between measures of aerobic fitness, speed and repeated sprint ability in full and part time youth soccer players. Journal of Sports Medicine and Physical Fitness,53, 9-16

Grammatikopoulos, V., Gregoriadis, A., \& Evridiki, Z. (2012). Acknowledging the role of motor domain in creativity in early childhood education. In O. Saracho (Ed.), Contemporary perspectives on research in creativity in early childhood education (pp. pp. 161-178). Charlotte, NC: Information age publishing.

Hair, J., Babin, B., Anderson, R., \& Black, W. (2019). Multivariate data analysis (8th ed). New Jersey, NJ: Pearson Educational, Inc. ISBN: 978-1473756540.

Hayes, A. (2018). Introduction to mediation, moderation, and conditional process analysis (2nd ed.). New York, NY: Guilford Press.

Hillman, C. H., Castelli, D. M., \& Buck, S. M. (2005). Aerobic fitness and neurocognitive function in healthy preadolescent children. Medicine \& Science in Sports \& Exercise, 37 (11), 1967-1974. doi:10.1249/01.mss.0000176680.79702.ce

Hristovski, R., Davids, K., Araújo, D., \& Passos, P. (2011). Constraints-induced emergence of functional novelty in complex neurobiological systems: A basis for creativity in sport. Nonlinear Dynamics, Psychology, and Life Sciences, 15(2), 175-206.

Kaufman, J. C., \& Baer, J. (2005). The amusement park theory of creativity. In J. C. Kaufman \& J. Baer (Eds.), Creativity across domains: Faces of the muse (pp. 321-328). Mahwah, NJ: Lawrence Erlbaum Associates.

Kaufman, J. C., Glăveanu, V. P., \& Baer, J. (2017). Creativity across different domains: An expansive approach. In J. C. Kaufman, V. P. Glăveanu, \& J. Baer (Eds.), The cambridge handbook of creativity across domains (pp. 3-8). New York, NY: Cambridge University Press.

Kaufman, J. C., Plucker, J. A., \& Baer, J. (2008). Essentials of creativity assessment. New York, NY: Wiley.

Kim, H. (2006). Can we trust in creativity tests? A review of the torrance tests of creative thinking (TTCT). Creativity Research Journal, 18(1), 3-14. doi:10.1207/s15326934crj1801_2

Kim, H. (2011). The creativity crisis: The decrease in creative thinking scores on the torrance tests of creative thinking. Creativity Research Journal, 23(4), 285-295. doi:10.1080/ 10400419.2011.627805

Kline, R. (2016). Principles and practice of structural equation modelling (3rd ed.). New York, The Guildford Press. ISBN: 9781462523344 .
Latorre Román, P. A., Pinillos, F. G., Pantoja Vallejo, A., \& Berrios Aguayo, B. (2017). Creativity and physical fitness in primary school-aged children. Pediatrics International, 59(11), 1194-1199. doi:10.1111/ped.13391

Leite, N., Baker, J., \& Sampaio, J. (2009). Paths to expertise in Portuguese national team athletes. Journal of Sports Science \& Medicine, 8(4), 560-566.

Lupu, E. (2012). Physical activities as a manner of lifelong developing creativity. Procedia-Social and Behavioral Sciences, 46, 1893-1898. doi:10.1016/j.sbspro.2012.05.398

Memmert, D. (2009). Noticing unexpected objects improves the creation of creative solutions-Inattentional blindness by children influences divergent thinking negatively. Creativity Research Journal, 21(2-3), 302-304. doi:10.1080/10400410802633798

Memmert, D. (2015). Teaching tactical creativity in sport: Research and practice. New York, NY: Routledge.

Memmert, D., Baker, J., \& Bertsch, C. (2010). Play and practice in the development of sport-specific creativity in team ball sports. High Ability Studies, 21(1), 3-18. doi:10.1080/13598139.2010.488083

Mujika, I., Santisteban, J., Impellizzeri, F. M., \& Castagna, C. (2009). Fitness determinants of success in men's and women's football. Journal of Sports Sciences, 27(2), 107-114. doi:10.1080/02640410802428071

Nevitt, J., \& Hancock, G. (2001). Performance of bootstrapping approaches to model test statistics and parameter standard error estimation in structural equation modeling. Structural Equation Modeling: A Multidisciplinary Journal, 8(3), 353-377. doi:10.1207/ S15328007SEM0803_2

O'Donoghue, P. (2010). Research methods for sports performance analysis. London: Routledge.

Pagona, B., \& Costas, M. (2008). The development of motor creativity in elementary school children and its retention. Creativity Research Journal, 20(1), 72-80. doi:10.1080/ 10400410701842078

Pesce, C., Croce, R., Ben-Soussan, T. D., Vazou, S., McCullick, B., Tomporowski, P. D., \& Horvat, M. (2019). Variability of practice as an interface between motor and cognitive development. International Journal of Sport and Exercise Psychology, 17(2), 133-152. doi:10.1080/ 1612197X.2016.1223421

Pesce, C., Masci, I., Marchetti, R., Vazou, S., Sääkslahti, A., \& Tomporowski, P. D. (2016). Deliberate play and preparation jointly benefit motor and cognitive development: Mediated and moderated effects. Frontiers in Psychology, 7, 349. doi:10.3389/fpsyg.2016.00349

Plucker, J., \& Beghetto, R. (2004). Why creativity is domain general, why it looks domain specific, and why the distinction does not matter. In R. J. Sternberg, E. L. Grigorenko, \& J. L. Singer (Eds.), Creativity: From potential to realization (pp. 153-167). Washington, DC: American Psychological Association.

Prieto, M. D., Parra, J., Ferrándo, M., Ferrándiz, C., Bermejo, M. R., \& Sánchez, C. (2006). creative abilities in early childhood. Journal of Early Childhood Research, 4(3), 277-290. doi:10.1177/1476718x06067580

Richard, V., Lebeau, J.-C., Becker, F., Boiangin, N., \& Tenenbaum, G. (2018). Developing cognitive and motor creativity in children through an exercise program using nonlinear pedagogy principles. Creativity 
Research Journal, 30(4), 391-401. doi:10.1080/ 10400419.2018.1530913

Runco, M., Millar, G., Acar, S., \& Cramond, B. (2010). Torrance tests of creative thinking as predictors of personal and public achievement: A fifty-year follow-up. Creativity Research Journal, 22(4), 361-368. doi:10.1080/ 10400419.2010.523393

Runco, M. A. (2014). Creativity: Theories and themes: Research, development and practice (2nd ed.). San Diego, CA: Academic Press.

Runco, M. A., \& Acar, S. (2012). Divergent thinking as an indicator of creative potential. Creativity Research Journal, 24(1), 66-75. doi:10.1080/10400419.2012.652929

Santos, S., Coutinho, D., Goncalves, B., Schollhorn, W., Sampaio, J., \& Leite, N. (2018). Differential learning as a key training approach to improve creative and tactical behavior in soccer. Research Quarterly for Exercise and Sport, 89(1), 11-24. doi:10.1080/02701367.2017.1412063

Santos, S., Jiménez, S., Sampaio, J., \& Leite, N. (2017). Effects of the skills4Genius sports-based training program in creative behavior. PLoS One, 12(2), e0172520. doi:10.1371/ journal.pone. 0172520

Santos, S., Memmert, D., \& Sampaio, J. (2020). Sports as a key route to ignite creativity. In New frontiers in psychology Shulamith Kreitler ed. New York, NY: Nova Science Publishers.

Santos, S., Memmert, D., Sampaio, J., \& Leite, N. (2016). The spawns of creative behavior in team sports: A creativity developmental framework. Frontiers in Psychology, 7, 1282. doi:10.3389/fpsyg.2016.01282

Sassi, R. H., Dardouri, W., Yahmed, M. H., Gmada, N., Mahfoudhi, M. E., \& Gharbi, Z. (2009). Relative and absolute reliability of a modified agility $\mathrm{T}$-test and its relationship with vertical jump and straight sprint. Journal of Strength and Conditioning Research, 23(6), 1644-1651. doi:10.1519/JSC.0b013e3181b425d2

Scibinetti, P. (2019). Creatività motoria. Come svilupparla in età evolutiva e anziana. Calzetti Mariucci, Ferriera di Torgiano.

Scibinetti, P., Tocci, N., \& Pesce, C. (2011). Motor creativity and creative thinking in children: The diverging role of inhibition. Creativity Research Journal, 23(3), 262-272. doi:10.1080/10400419.2011.595993

Sternberg, R. J., \& Lubart, T. I. (1999). The concept of creativity: Prospects and paradigms. In R. J. Sternberg (Ed.), Handbook of creativity (pp. 3-15). New York: Cambridge University Press.

Tekin, M., \& Güllü, M. (2010). Examined of creativity level of primary school students who make sports and do not make sports. Procedia - Social and Behavioral Sciences, 2 (2), 3351-3357. doi:10.1016/j.sbspro.2010.03.514

Torrance, E. (1981). Thinking creatively in action and movement. Bensenville, IL: Scolastic Testing Service.

Wassenberg, R., Feron, F. J., Kessels, A. G., Hendriksen, J. G., Kalff, A. C., Kroes, M., ... Vles, J. S. (2005). Relation between cognitive and motor performance in 5- to 6-yearold children: Results from a large-scale cross-sectional study. Child Development, 76(5), 1092-1103. doi:10.1111/ j.1467-8624.2005.00899.x

Williams, J., \& Mackinnon, D. P. (2008). Resampling and distribution of the product methods for testing indirect effects in complex models. Structural Equation Modeling: A Multidisciplinary Journal, 15(1), 23-51. doi:10.1080/ 10705510701758166 